\title{
EM BUSCA DA PALAVRA dO MEStRe
}

\author{
LUCIO COSTA: SOBRE ARQUITETURA, \\ de Lucio Costa. Alberto Xavier (org.). Porto Alegre: UniRitter, 2007. \\ OTAVIO LEONÍDIO
}

A publicação em versão fac-símile de Lucio Costa: sobre arquitetura é um acontecimento editorial extraordinário, sob diversos aspectos. Publicado originalmente em 1962 pelo Centro dos Estudantes Universitários de Arquitetura da Universidade do Rio Grande do Sul, o livro foi a primeira coletânea mais ou menos compreensiva dos escritos do grande artífice intelectual e político da "arquitetura moderna brasileira": Lucio Costa (1902-98).

Mentor de acontecimentos cruciais para a renovação da arquitetura nacional - com destaque para a vinda de Le Corbusier ao Brasil em 1936, da qual resultou o consagrado projeto do edifício-sede do Ministério da Educação e Saúde (MES) —, além de autor dos enunciados públicos que, por trinta anos, vinham sustentando-a política $e$ sobretudo conceitualmente, Costa, então com 60 anos, já gozava à época do prestígio reservado aos grandes mestres. $\mathrm{E}$ foi, de fato, em busca da palavra do "eminente mestre" que um jovem estudante de arquitetura, Alberto Xavier, pôs-se a coligir obstinadamente textos dispersos e esquecidos, alguns deles publicados por Costa ainda nas décadas de 1920 e 1930. Como afirmava Xavier em nota informativa à edição original, "impunha-se, pois, de nossa parte, um delicado e

[1] Xavier, Alberto. "Nota informativa". In: Costa, Lucio. Lucio Costa: sobre arquitetura. Porto Alegre: CEUA, 1962, p. 8. paciente esforço no sentido de reconstituição de todo seu acervo de trabalho, para nós verdadeiro relicário" ${ }^{\prime}$.

O surpreendente, bem entendido, era o fato de que, dada sua notória importância, tais escritos jamais tivessem sido compilados e reunidos em livro, e que só o fossem de modo, digamos, clandestino, isto é, sem que Costa tivesse notícia da empreitada levada a termo à sua revelia. Em depoimento de 2002 , Xavier relatou a reação de Costa quando finalmente tomou conhecimento da publicação: 
Num fim de tarde do ano de 1962 subi os elevadores do edifício do Ministério da Educação, até chegar ao sétimo andar, onde estava instalado o SPHAN [Instituto do Patrimônio Histórico e Artístico Nacional]. Havia, conforme previamente combinado, uma equipe de recepção - espécie de batedores -, para facilitar as coisas. Lá estavam, entre outros, Alcides da Rocha Miranda e uma figura que nunca esqueci, dado seu peculiarsorrisoSimeão Leal. Dirigiram-se comigo à sala onde Lucio Costa trabalhava"a toca do doutor Lucio", como era conhecida. Foram logo dizendo: "Olha, doutor Lucio, tem uns estudantes...". Colocaram no plural, repetindo: "tem uns estudantes aí do Rio Grande do Sul que vieram trazer um presente para o senhor". "Estudantes" no plural para eu não ficar sozinho e "presente" para atenuar uma possivel reação adversa. Ele abriu o livro, surpreso ao ver do que se tratava, olhou para os dois colegas, olhou para mim, e disse: "Isto éum caso de polícia!"2.

Os motivos de tamanha contrariedade podiam parecerenigmáticos para o jovem Xavier³, mas hoje, passados 45 anos, eles parecem razoavelmente claros.Afinal, se havia algo de que Lucio Costa jamais estivera disposto a abrir mão era o controle sobre o uso de suas palavras. Et pour cause: fora em associação direta com os extraordinariamente eficazes enunciados públicos costianos que, desde 1936 pelo menos, as obras de arquitetos como Oscar Niemeyer, Affonso Eduardo Reidy, Jorge Machado Moreira e tantos outros (incluindo as dele próprio, Costa) haviam logrado firmar-se como legítima expressão de uma arquitetura moderna $e$ brasileira. Uma arquitetura, portanto, dotada de inaudita capacidade de atender às rigorosas exigências estéticas definidas, desde meados da década de 1920, pelo movimento modernista - Mário e Oswald de Andrade à sua frente - e que por isso mesmo se firmara, entre as décadas de 1930 e 1950, como produto cultural único num Brasil que, por regra, sistematicamente fracassara no sempiterno desejo de ser moderno. Tal eficácia conferia a ele, Costa, uma autoridade sem par, da qual muito cedo tomara consciência e de que lançava mão de modo consciente e estratégico, elegendo os temas que, a seu juízo, deveriam ser abordados a cada momento, os veículos adequados a cada "ato de fala", os fóruns (públicos ou privados) em que disputas específicas deveriam ser travadas.

Desse ponto de vista, a simples idéia da reunião por terceiro e à sua revelia de conjunto tão diversificado e heterogêneo de textos (com destaque para os enunciados públicos) constituía algo particularmente descabido e muito provavelmente inoportuno. Descabido e inoportuno, entenda-se, do ponto de vista de quem, uma vez vencida uma primeira fase da "Guerra Santa" (a guerra pela obtenção de uma hegemonia forte o suficiente para assegurar, na década de 1930 e início da de 1940, a difusão dos projetos arquitetônicos por ele considerados verda-
[2] Xavier, Alberto. "Depoimento". In: Nobre, Ana Luiza e outros. Um modo de ser moderno: Lucio Costa e a crítica contemporânea. São Paulo: Cosac Naify, 2004, p. 311.

[3] Ibidem 
[4] Arantes, Otília B. F. "Resumo de Lucio Costa".Folha de S. Paulo, "Mais!", 24/2/2002, p. 6-11; Martins, Carlos A. F.Arquitetura Estado no Brasil. Elementos para uma investigação sobre a constituição do discurso moderno no Brasil: a obra de Lucio Costa (1924-1952). São Paulo, dissertação de mestrado, FFLCH-USP, 1987.
[5] Na prática, tal característica faz com que o trabalho de compilação da obra escrita de Lucio Costa se torne um verdadeiro quebra-cabeça - trabalho ainda hoje longe de ser sido concluído.

[6] Destacaria, entre outros, os trabalhos - pordefinição, críticos - de Luís Espallargas Gimenez, Carlos Alberto Ferreira Martins e Otília Beatriz Fiori Arantes. deiramente modernos), dedicava-se, desde 1945 pelo menos, a consolidar uma memória da arquitetura moderna brasileira4. Obviamente, não uma memória qualquer, mas uma memória coesa e coerente, na qual acontecimentos presentes se explicavam por eventos pretéritos específicos, e cujo significado, bem entendido, era definido por ele próprio, Lucio Costa. O surpreendentemente rápido florescimento da arquitetura moderna no Brasil, por exemplo, explicava-se sem pena: fora ocasionado, na interpretação de Costa, pelo contato de primeira-mão com as idéias de Le Corbusier. Como era de supor, a autoconsciência da extraordinária eficácia desses enunciados tinha como conseqüência um enorme cuidado com seu uso, o que excluía, naturalmente, a possibilidade de que fossem usados, digamos, livre ou inadvertidamente. Ora, era exatamente isso o que fizera Xavier: um caso de polícia!

\section{UM LIVRO ALTERNATIVO}

Contudo, reside precisamente aí o extraordinário interesse de Lucio Costa:sobre arquitetura. Não tendo sido organizado por Costa, o livro não padece das recorrentes "correções" posteriormente operadas pelo autor em seus textos (supressão de trechos, alteração de palavras e frases, refusão de textos, alterações de títulos etc) 5 . A comparação com o principal livro publicado em vida por Costa - Lucio Costa:registro de uma vivência, de 1995 - é nesse sentido reveladora e atesta que o "clandestino" Lucio Costa:sobre arquitetura não é a rigor um livro menos completo e abrangente que seu concorrente, digamos, "oficial". Na verdade, trata-se de um livro alternativo, por meio do qual pode-se ter acesso às versões originais de textos que, em Registro de uma vivência, foram muitas vezes alteradas. Tome-se como exemplo o seminal "Razões da nova arquitetura", publicado pela prestigiosa Revista da Diretoria de Engenharia da Prefeitura do Distrito Federal, em janeiro de 1936: a versão publicada em Registro perdeu nada menos do que 4 parágrafos inteiros (108 linhas!), além de outras correções por assim dizer estratégicas, sem que nada disso fosse sinalizado ao leitor.

O fato de tais adulterações terem sido ignoradas ou pouco valorizadas pela historiografia atesta em última instância a grande dificuldade ainda hoje vigente quando se trata de abordar historicamente os enunciados de personagem tão importante quanto Lucio Costa. Averdadeé que, malgrado alguns raros estudos acadêmicos dotados de vocação crítica $^{6}$, a obra escrita de Lucio Costa permanece lida segundo a chave interpretativa estabelecida - a posteriori - por... Lucio Costa. Chave interpretativa fundada desde logo no princípio da coerência biográfica, quer dizer, em função de uma auto-imagem definida retrospectivamente pelo próprio Costa, em cujo quadro enunciados históricos (entendam-se ações perpetradas em um contexto específico e com fins 
igualmente específicos e portanto datados) passam a ser interpretados em função de desdobramentos futuros - o principal deles, a definição ou consolidação de um coeso e coerente "pensamento" de Lucio Costa. Obviamente, muitos fatores contribuíram para esse estado de coisas, entre os quais destaca-se, a par da extraordinária sofisticação das formulações de Costa, a longevidade do homem e de sua incansável ação em prol de um projeto de vida: a constituição física e discursiva de uma certa arquitetura moderna brasileira7. O que, bem entendido, não exime os historiadores brasileiros da responsabilidade de ter abdicado, por décadas a fio, da tarefa primordial de abordar os enunciados costianos historicamente (leia-se, criticamente), preferindo, não raro, simplesmente corroborar a auto-imagem (e de si mesmo e de sua "arquitetura moderna brasileira") propagandeada pelo "doutor Lucio".

Vale notar, a propósito, que, desse ponto de vista, Costa não tinha muito do que se queixar da livre compilação feita em 1962 (mantida na edição atual) por Alberto Xavier.Afinal, não obstante a intenção inicial de fazer de Lucio Costa: sobre arquitetura uma obra completa, ou pelo menos o mais completa possível (em virtude das alegadas dificuldades encontradas no processo de organização da obra) ${ }^{8}$, não são poucas nem pouco significativas as lacunas deixadas pelo livro. Sabe-se hoje, disponibilizados os arquivos do SPHAN, do Centro de Pesquisa e Documentação de História Contemporânea do Brasil (CPDOC) da Fundação Getulio Vargas (FGV) e da Fundação Le Corbusier - e graças às pesquisas pioneiras de Lucia Gouvêa Vieira e Maria Cristina Burlamaqui, Carlos Alberto Ferreira Martins, Maria Angélica da Silva, Cecília Rodrigues dos Santos, Margareth da Silva Pereira, Vasco Caldeira e Romão da Silva Pereira, Maurício Lissovsky e Paulo Sérgio de Sá, Simon Schwartzman, Helena Bomeny e Vanda Ribeiro Costa, José Pessoa, e do próprio Alberto Xavier - que, até 1962, o conjunto da obra escrita de Lucio Costa, entre enunciados públicos e documentos privados (cartas, relatórios, pareceres) ultrapassa a casa dos 200 itens, contra os 45 reunidos em Lucio Costa:sobre arquitetura. O dado relevante não é todavia de ordem quantitativa, é de recorte. Pois, significativamente, o livro não reproduz alguns dos mais importantes (sobretudo do ponto de vista do historiador intelectual) textos produzidos por Costa nas décadas de 1920 e 1930. O grande destaque cabe aos textos publicados por Lucio Costa quando ainda integrava o chamado movimento neocolonial, e aqueles que publica quando, após abandonar a tendência, envolve-se em polêmica pública com seu grande campeão - o médico e amante das artes José Marianno Filho (de quem Costa, até um ano antes, havia sido o mais dileto protégé). Ora, a exclusão de conjunto tão significativo de textos (de quase uma dezena de textos publicados por Costa até 1931, Lucio Costa:sobre arquitetura traz apenas um)9, todos publicados em jornais de grande circulação, parece indi-
[7] Guerra, Abílio. Modernidade e tradição: montagem discursiva da arquitetura moderna brasileira. Campinas (SP): tese de doutorado, Departamento de História, Unicamp, 2002.

[8] Em sua apresentação, Alberto Xavier afirma que das obras de Lucio Costa já divulgadas, "não constam desta coletânea apenas duas, ambas por demais conhecidas: 'Arquitetura dos jesuítas no Brasil' e o prefácio de 'Antônio Francisco Lisboa'”. Op. cit, p. 10.

[9] Além de um pequeno pronunciamento feito por Costa em $1931 \mathrm{e}$ publicado nos anais da ENBA. 
[10] Xavier, Alberto. "Impertinência necessária". In: Costa, Lucio. Lucio Costa: sobre arquitetura (org. Alberto Xavier). Porto Alegre: UniRitter, 2007, p.XVII. car uma espécie de concordância tácita entre certa cultura arquitetural brasileira deépoca (1962) e os fundamentos básicos do desenho dado por Costa à sua autobiografia intelectual. Autobiografia fundada, entre outras coisas, no postulado de uma suposta separação radical entre as idéias anteriores a 1930 (tidas como arcaicas) e as posteriores a essa data (tidas como modernas). A existência dessa concordância tácita parece confirmar-se numa das seções finais de Lucio Costa:sobre arquitetura, consagrada à "relação de obras realizadas" pelo arquiteto: significativamente, não há menção às obras projetadas e construídas por Costa no período anterior a 1931 - as obras que fizeram a fama do prolífico e bem-sucedido arquiteto eclético e neocolonial.

Não surpreende portanto que, uma vez passado o choque inicial da descoberta do livro "clandestino", Costa logo percebesse que, todas as contas feitas, e não obstante o incômodo da publicação de uma ou outra impropriedade (a mais doída, sem dúvida, a afirmação, feita em 1929, de que o Aleijadinho "tinha espírito de decorador e não de arquiteto" e que sua obra, expressão de "ódios mesquinhos" e do "seu "íntimo torturado e recalcado", "nunca esteve de acordo com o verdadeiro espírito geral de nossa arquitetura"), a seleção feita por Xavier não era absolutamente impertinente, muito menos um "caso de polícia". Afora o texto sobre o Aleijadinho (excluído como era de esperar de Registro de uma vivência), a seleção não era absolutamente inoportuna, cabia apenas aprimorá-la, algo que supunha operar algumas correções.

\section{ESCREVENDO PARA A POSTERIDADE}

O interesse adicional da edição que ora se publica reside precisamente aí. Pois o que se reproduziu em fac-símile não foram apenas as páginas originais de Lucio Costa:sobre arquitetura, mas igualmente as anotações marginais feitas pelo próprio Costa (a lápis, como de costume) no exemplar recebido das mãos de Alberto Xavier numa distante e tensa tarde de $1962^{10}$. Essa marginália imprime à nova edição uma nova camada de significados, uma vez que permite entrever o que, aos olhos do consagrado sexagenário, merecia ser reparado, e especular, em cada caso, os porquês.

Desse ponto de vista, vale dizer desde logo que a impressão imediata que se tem quando se lêem as anotações de Costa é de que, previsivelmente, não parecem ter sido feitas para si próprio ou exclusivamente para Alberto Xavier, mas para a posteridade. Diz-se "previsivelmente", porque àquela altura Costa obviamente já tinha plena consciência de que tudo o que escrevesse viria ao mundo com o status de documento histórico, vale dizer, algo que, cedo ou tarde, seria objeto de registro, análise e interpretação de estudiosos. Cumpria pois deixar registrado o que, em uma leitura autorizada, não estava 
correto ou suficientemente claro. Claro o suficiente, repare-se, para que não restasse muita margem a interpretações divergentes daquelas estabelecidas por Costa - a ele e só a ele cabendo, pordireito, o trabalho interpretativo referente à arquitetura moderna brasileira.

É de fato isso o que se percebe ao analisar o conteúdo das notas marginais apostas a Lucio Costa:sobre arquitetura (feitas, presumivelmente, de forma total ou parcial, em 1966, uma vez que, em pelo menos duas ocasiões, Costa marcou "30/I/66"). Basicamente, são três gêneros de anotações: 1) revisão ou simples refutação do conteúdo original dos textos;2) comentários à guisa de esclarecimento ou complementação informativa do conteúdos original dos textos;3) correções de dados fornecidos pelo organizador, além de queixas ou reprovações quanto ao conteúdo ou formato da reprodução dos textos originais. Na primeira categoria, destacam-se os comentários feitos ao texto sobre o Aleijadinho. Como esperado, trata-se de reiterar que as idéias anteriores a 1930 não tinham muito cabimento e que, em todo caso, eram idéias que não se articulavam com formulações posteriores. Uma das notas apostas ao texto de 1929 é suficientemente eloqüente:

Equívoco. Errado. Pura ignorância. Voltado apenas para a beleza das obras do s. XVII e começo do XVIII, eu ainda não estava então preparado para perceber o altíssimo teor de sua obra de arquiteto e escultor.

Na segunda categoria, há comentários mais ou menos reveladores, e alguns simplesmente prosaicos. Sobre o projeto para a Cidade Universitária do Brasil (de 1936), anota:

Esplêndido projeto. É uma pena que por causa de dois energúmenos presunçosos - o [Inácio de $]$ Amaral e o [Ernesto de] Souza Campos-, a oportunidade se perdesse. Enquanto isto, se arrasta o incrível Fundão!

Sobre "Ensino do desenho" - proposta de revisão curricular do ensino do desenho no curso ginasial, elaborada no âmbito da reforma do ensino secundário posta em prática por Gustavo Capanema, sobretudo durante o Estado Novo -, escreve, em tom de lamento: "É incrível como um quarto de século decorrido, este programa não serviu para nada" (p.160). A propósito de "Considerações sobre a arte contemporânea", de 1952, um dos mais extensos textos escritos por Lucio Costa, uma única palavra: "perfeito" (p. 229).

Na terceira categoria, destaca-se, entre outros, a correção à nota do organizador sobre a autoria do projeto da Cidade Universitária do Brasil, segundo a qual o projeto da equipe de Costa teria sido elaborado 
[11] Leonídio, Otavio. Carradas de razões. Lucio Costa e a arquitetura moderna brasileira (1924-1951). Rio de Janeiro: tese de doutorado, Departamento de História, PUC-Rio, 2005, p. 171-2.

[12] O depoimento de Niemeyer consta de Wisnik, Guilherme (org.). Orisco. Lucio Costa e a utopia moderna. Rio de Janeiro: Bang Bang Filmes, 2003, p. 110-20. "tendo Le Corbusier como consultor". O comentário marginal de Lucio Costa ("Pelo contrário, este projeto resultou da rejeição pelo Conselho de professores do projeto Le Corbusier.Adotou-se aqui precisamente o partido oposto - centrado e denso em vez de rarefeito e periférico. Le Corbusier não teve qualquer participação", p. 67) atesta como, passados trinta anos, a definição da autoria dos projetos desenvolvidos na seqüência da estadia de Le Corbusier no Brasil, em 1936 (MES e Cidade Universitária), era ainda uma questão de honra para o campeão da arquitetura moderna brasileira. Persistia intacta, percebese, a necessidade de reiterar - para a posteridade - que, tanto quanto o edifício do ministério, o projeto da Cidade Universitária era nosso, e não dele. Que a noção de "projeto" empregada por Costa nessa e noutras ocasiões raramente tenha sido objeto de análise crítica apenas atesta como os enunciados de Costa foram eficazes em definir o modo como um sem-número de questões deveria ser discutido e interpretado. Eficazes, repare-se, até os dias de hoje; afinal, em inteira conformidade com a leitura costiana, persiste o consenso de que o projeto no MES é de autoria da equipe brasileira, a Le Corbusier cabendo apenas a responsabilidade por certo "risco original", de significado bastante enigmático ${ }^{11}$. Surpreendente ou não, foi Oscar Niemeyer quem, muito recentemente, chamou a atenção para a discrepância entre a abordagem projetual de Le Corbusier e aquela empregada pelos arquitetos do grupo de Costa até terem contato direto com o francês. Ainda que, como de costume, Niemeyer esteja implicitamente querendo destacar seu protagonismo no projeto em questão, pode-se perceber na declaração o reconhecimento de que, à falta da incorporação da démarche projetual lecorbusieriana, nenhum dos dois projetos teria adquirido a forma que têm - e o MES, em especial, muito provavelmente teria até hoje aspecto de "múmia", jocoso apelido que lhe fora dado por Le Corbusier ${ }^{12}$.

$\mathrm{Na}$ mesma categoria de anotações estão os extensos comentários apostos à "nota biográfica" preparada por José Carlos Coutinho. Aqui se destaca o esforço de Costa em esclarecer o papel que desempenha nos cruciais episódios do descarte do projeto de Archimedes Memória para o edifício do MES (projeto vencedor do concurso público organizado por Capanema) e da vinda de Le Corbusier ao Brasil, em 1936. De acordo com o biógrafo,

[... Lucio Costa, apoiado por Carlos Drummond de Andrade, Mário de Andrade, Rodrigo Mello Franco de Andrade e Manuel Bandeira tomou a iniciativa de convencer o ministro Gustavo Capanema da necessidade de não aproveitar os projetos premiados e da imperiosa vinda de Le Corbusier para orientar a confecção de um projeto condizente com a época e repercussão da obra. (p.352) 
A refutação por parte de Costa é peremptória: "Não é verdade. Fui convidado a elaborar novo projeto sem haver interferido de qualquer modo. A deliberação do convite a Le Corbusier é muito posterior. (p. 352)". O que está em jogo para Costa não é - como pode parecer à primeira vista - relativizar seu protagonismo no episódio da vinda do arquiteto francês, senão, ao que parece, deixar claro que não teve participação no processo que resultou no descarte do projeto de Memória. O fato de Lucio Costa ter enviado a Capanema proposta para elaboração de novo projeto para o edifício do MES algumas semanas antes do comunicado oficial do descarte do projeto de Memória (a carta-proposta de Costa é de 8 de janeiro de 1936, ao passo que o ofício de Gustavo Capanema a Getúlio Vargas é de 11 de fevereiro. O episódio sóvem a ser noticiado pela imprensa, em tom de denúncia, no início de março do mesmo ano) ${ }^{13}$ sugere todavia que a ação de Costa pode não ter sido tão republicana quanto quer fazer crer. Nesse caso, os comentários marginais parecem querer corroborar dois dos traços mais popularmente aceitos (conforme a auto-imagem difundida pelo autor) da "personalidade" de Lucio Costa: a correção e a generosidade.

Ainda na terceira categoria encontra-se a correção da datação de "Razões da nova arquitetura" - texto tido por muitos estudiosos como a pedra de toque conceitual da "arquitetura moderna brasileira". Sobre o contexto de elaboração desse texto, publicado em janeiro 1936, sempre persistiu alguma confusão. Na "Autobiografia" que prepara especialmente para o livro Depoimento de uma geração - coletânea de textos publicada por Alberto Xavier em 1987-, Costa escreve: "Em 35 fui professor de pós-graduação na Universidade do Distrito Federal de Anísio Teixeira ('Razões da nova arquitetura')"14 — dando portanto a entender que o texto teria sido produzido nesse contexto específico. A informação é confirmada em Registro de uma vivência, no qual o arquiteto refere-se a "Razões" como o "programa para um curso de pós-graduação do Instituto de Artes dirigido por Celso Kelly na antiga Universidade do Distrito Federal, criada por Anísio Teixeira com a participação de Mário de Andrade, Gilberto Freyre, Prudente de Moraes Neto, Sérgio Buarque de Holanda, Portinari e Celso Antonio, entre outros" ${ }^{15}$. A correção feita por Costa na datação proposta por Xavier ("1933-5", em vez da data consignada por Xavier, "1930")16 é reveladora: correta ou não (não há, salvo engano, fontes documentais disponíveis a respeito), demonstra em todo caso que, para o Lucio Costa de 1966, aquele seminal texto fora redigido, ou antes, berçado, ao longo dos extensos e férteis anos de "chômage" (1932-35) - anos em que, conforme reconhecera em carta ao próprio Le Corbusier, Costa dedicara-se a dar "a volta completa" no "bloco límpido", de "imponente grandeza", que era o pensamento do mestre francês ${ }^{17}$. Informação, de
[13] Lissovsky, Maurício \& Sá, Paulo Sérgio M. Colunas da educação: a construção do Ministério da Educação e Saúde. Rio de Janeiro: IPHAN, 1996, p. 25-9.

[15] Costa, Lucio.Lucio Costa: registro de uma vivência. São Paulo: Empresa das Artes, 1995, p. 108, cabeçalho.

[16] Observe-se que tanto na edição original de Lucio Costa: sobre arquitetura como na presente, optou-se "sempre que possível" por datar os textos em função de sua suposta data de elaboração, e não de publicação.

[17] Costa, Lucio. "Carta a Le Corbusier", 26/6/1936. Apud Santos e outros. Le Corbusier e o Brasil. São Paulo: Tassela/Projeto, 1987, p.141-2. 
[18] Costa, Lucio. "Carta depoimento". O Jornal, Rio de Janeiro, 14/3/ 1948.

[19] Martins, Carlos. "Gregori Warchavchik: combates pelo futuro". In. Warchavchik, Gregori.Arquitetura do século XX e outros escritos (org. Carlos A. F. Martins). São Paulo: Cosac Naify, 2006. resto, facilmente confirmável pela comparação entre as formulações presentes em "Razões" e o ideário do primeiro Le Corbusier.

\section{SILÊNCIOS ELOQÜENTES}

Contudo, tão ou mais significativos que os comentários são alguns eloqüentes silêncios, leia-se, ausências de comentários a textos sobre cujas idéias ou posturas poder-se-ia talvez esperar algum tipo deesclarecimento da parte de um Costa sexagenário (e num momento em que, presumivelmente, a "guerra santa" em favor da sua arquitetura moderna brasileira já estava vencida). Dentre esses silêncios, dois em especial chamam a atenção do leitor. O primeiro refere-se à resposta, publicada em 1948, à censura que lhe fizera algumas semanas antes o jornalista Geraldo Ferraz.A acusação:ter negligenciado o pioneirismo do arquiteto Gregori Warchavchik (1896-1972) para a renovação da arquitetura brasileira. A resposta de Costa era dura - e dura especialmente para com Warchavchik:

O que está em jogo e aguça a curiosidade perplexa dos arquitetos e críticos de arte europeus e americanos não é propriamente saber quando, nem como ou por quem a nova concepção arquitetônica foi trazida para o nosso país, mas, sim, por que motivo, enquanto por toda a parte a arquitetura nova conservou-se mais ou menos limitada às fórmulas do conhecido ramerrão, ela irrompeu aqui, bruscamente, cerca de doze anos depois de ter sido experimentada pela primeira vez, sem maiores conseqüências, com tamanha graça e segurança de si, com feição tão particular e tão desusada e desconcertante vigor? Essa a questão que importa e para cujo esclarecimento a obra pioneira do nosso querido Gregório [sic] e a personalidade singulardo Flávio [de Carvalho] de nada podem adiantar, porquanto o que se passou até aqui teria ocorrido, sem alteração sequer de uma linha, ainda quando o primeiro houvesse realizado a sua obra alhures, e o segundo espairecesse exilado, desde bebêe, em Paris ou na Passárgada ${ }^{18}$.

Se a resposta de 1948 fora dura, o silêncio de 1966 parecia indicar que, passados quase vinte anos, não havia mesmo nada a acrescentar àquela inequívoca - e algo polêmica - interpretação. E isso não obstante o melancólico e persistente processo de marginalização em que, cada vez mais, se via enredada a obra e a figura do "nosso querido Gregório". Marginalização, como se vê, devida em grande medida à eficácia das interpretações costianas ${ }^{19}$.

O segundo silêncio refere-se ao texto "Oportunidade perdida" título à resposta dada por Lucio Costa às críticas que, em visita ao Brasil (1953), o arquiteto e artista plástico suíço Max Bill fizera à arquitetura contemporânea brasileira. Dizendo-se conhecedor de "quase tudo o que 
até agora se publicou no estrangeiro sobre a arquitetura brasileira”, Bill era taxativo: "[...] a arquitetura moderna brasileira padece um pouco desse amor ao inútil, ao simplesmente decorativo" 20 . Uma vez mais, o contra-ataque de Costa era duro, quase grosseiro; mais do que refutar as idéias, tratava-se de desqualificar o crítico, que “[...] não é, a rigor, nem arquiteto, nem pintor ou escultor, mas sim fundamentalmente um delineador de formas ('designer') [...]". Se nossa arquitetura denotava certo "barroquismo", isso apenas demonstrava, nas palavras de Costa, "não descendermos de relojoeiros, mas de fabricantes de igrejas barrocas". O fato de que, passados mais de dez anos, não houvesse nada a ser acrescentado à sumária desvalorização da própria noção de design, parece indicar que: ou bem Lucio Costa permanecia desvalorizando per si o significado do projeto construtivo levado a termo no campo da arquitetura, sobretudo por Walter Gropius (de quem Bill era discípulo) em sua Bauhaus (em cujo quadro a distinção entre design e arquitetura é no mínimo problemática) ${ }^{21}$; ou bem persistia julgando que, no caso brasileiro, por diversas razões (a principal delas, a incipiência de nossa industrialização), o caminho só poderia seroutro edeveria permanecervinculado (em 1966 tanto quanto em 1953 e em 1936) a um projeto alternativo, fundado no preceito lecorbusieriano da conjugação entre técnica e beleza ${ }^{22}$.

\section{SOBRE ALGUNS CRITÉRIOS EDITORIAIS}

Sobre a edição em fac-símile que ora se publica deve ser dito apenas que se ressente de algumas opções de editoração. A primeira delas é o uso de uma mesma cor (vermelho-terra) tanto para os desenhos que originalmente ilustravam os textos de Costa como para as notas marginais posteriormente apostas ao volume pelo arquiteto, fato que pode com facilidade confundir o leitor. $O$ mesmo pode ser dito das correções - de ortografia, datação etc. - operadas na edição original: em se tratando de edição fac-símile, melhor teria sido manter intocada a versão original e operar as correções em nota de rodapé.

Igualmente duvidosa - uma vez mais, para uma edição que se auto-intitula fac-similar — foi a opção de substituir alguns desenhos constantes da edição original. Não se compreende por quê, por exemplo, os desenhos que, na edição de 1962, ilustravam o texto "Considerações sobre a arte contemporânea", foram substituídos por versões alternativas (ao que parece, pelas versões constantes de Registro de uma vivência). As dúvidas que daí resultam são muitas: os desenhos da primeira edição teriam sido publicados com erros? Se não o foram, o que justificaria a adoção deversões "aprimoradas"? O fato de constarem de Registro de uma vivência? A advertência feita pelo organizador na apresentação não parece suficientemente esclarecedora:
[20] Bill, Max. "Max Bill critica a nossa moderna arquitetura". Manchete, Rio de Janeiro, 13/7/1953. Apud Bandeira,João(org.).Arte concreta paulista: documentos. São Paulo: Cosac Naify, Centro Universitário Maria Antônia da USP, 2002, p. 32-3.

[21] O tema vem sendo tratado de mono pioneiro por Ana Luiza Nobre em sua pesquisa de doutorado, desenvolvida atualmente no Programa de Pós-Gradução em História Social da Cultura da PUC-Rio.

[22] Argan, Giulio Carlo. "Arquitetura moderna no Brasil". In: Comunità, Roma,n.24,1954,p.48-52.Apud Xavier, Alberto (org.). Depoimento de uma geração. São Paulo: Cosac Naify, 2003, p. 174. 
[23] Há notas em que Costa protesta pela ausência de ilustrações e nem por isso a solicitação foi atendida pelo organizador.
[24] Costa, Lucio. "Carta a Alberto Xavier", 13/10/1971.

[25] Reproduzida (fac-símile) em Leonídio, Otavio, op. cit, p. 367.
Com relação a erros de ortografia, datas, nomes de lugares, etc., foram agora corrigidos no próprio texto, enquanto as observações de Lucio Costa sobre seus desenhos - ora ausentes na edição original, ora publicados com fisionomia refeita -, foram substituídos quando possível, como é o caso das ilustrações às páginas 206, 207 e 209. (p.XVII, realces meus)

Significa isso que, em caso de inclusão ou substituição de desenhos, suprimiu-se, em troca, as notas marginais? E mesmo que isso não tenha ocorrido, qual foi o critério adotado para decidir-se o que era e o que não era "possível" corrigir ${ }^{23}$ ? O reconhecimento de erro cometido quando da organização original do material? A veemência da nota-protesto de Lucio Costa?

Dito isso, é preciso destacar que a republicação de Lucio Costa:sobre arquitetura - cuja versão original, esgotadíssima, há muito transformara-se em peça de colecionador - é uma grande contribuição oferecida (de parte deste extraordinário pesquisador que é Alberto Xavier, a cuja ação os estudiosos da arquitetura brasileira tanto devem) a todos aqueles que se interessam pelo melhor pensamento brasileiro do século XX, arquitetural mas não apenas. Para o leitor contemporâneo, é uma oportunidade rara de ter contato direto, em suas versões originais, com os extraordinários textos de Lucio Costa - com sua insuperável redação e suas sofisticadíssimas formulações. Se há algo a ser lamentado, na ocorrência, é apenas o fato de que a reedição não tenha ocorrido antes, conforme planejado por Alberto Xavier. Em carta endereçada a este, datada de 13 de outubro de 1971, Lucio Costa deixava todavia claro seu juízo a respeito do projeto:

Prezado Alberto Xavier, estranho a sua iniciativa, porquanto não faz sentido, quando se ultima o preparo do livro definitivo a meu respeito, prejudicar-lhe o lançamento reeditando a publicação feita pelo CEUA [Centro de Estudantes Universitários de Arquitetura] de Porto Alegre à minha revelia. Presumia que, depois das conversas havidas, já estivesse claro no seu espírito ser este livro da $U_{n} B$ - onde se traduz de modo coerente o meu pensamento - apalavrafinal 24 .

Quarenta e cinco anos após a publicação original de Lucio Costa: sobre arquitetura, é tempo novamente de sair em busca da palavra do mestre, digo, de Lucio Costa 25 .

OTAVIO LEONÍDIO, arquiteto, é doutor em história e professor do curso de Arquitetura e Urbanismo e do Programa de Pós-Graduação em Design da Pontifícia Universidade Católica (PUC-Rio). 